\title{
EFEITO DO TAMANHO DE AGREGADOS SÔBRE O CRESCIMENTO E SISTEMA RADICULAR DO MILHO ( $\left.{ }^{1}\right)$
}

F. GrohmanN e JosÉ Pereira DE Queiroz Neto, engenheiros-agrônomos, Seção de Agrogeologia, Instituto Agronômico

\section{SINOPSE}

Agregados das classes de tamanho 7-4, 4-2, 2-1 e $<1 \mathrm{~mm}$, dos solos latossolo roxo e podzólico vermelho amarelo-orto, foram colocados em vasos de vegetação, para permitir a observação do crescimento da parte aérea e do sistema radicular do milho naqueles diferentes tamanhos de agregados.

Verificou-se que o comportamento das plantas foi diferente num e noutro solo. No latossolo roxo, a classe de tamanho de agregados mais conveniente para o crescimento da parte aérea e do sistema radicular foi a $<1 \mathrm{~mm}$; no podzólico vermelho amarelo o maior desenvolvimento da planta se deu nas classes de tamanho 4-2 e $2-1 \mathrm{~mm}$.

A causa da variação do crescimento das partes aéreas e do sistema radicular parece estar ligada ao comportamento físico do solo. Assim, para os podzólicos vermelho amarelo-orto a pulverização do solo antes do cultivo provocaria uma compactação excessiva, dificultando o desenvolvimento do sistema radicular; o latossolo roxo não apresentaria êsse inconveniente, possibilitando um trabalho mais intenso da terra para o cultivo.

\section{1 - INTRODUÇÃO}

Foi possível verificar que a estrutura, tanto do latossolo roxo quanto do podzólico vermelho amarelo-orto, sofre as influências dos trabalhos agrícolas e das adubações $(2,3,4,7,8)$.

Observou-se, também, que os agregados de diferentes tamanhos do latossolo roxo apresentam variação sistemática de certas características físicas e químicas, ao contrário do podzólico vermelho amarelo-orto (9). As diferentes formas de uso e as adubações, além disso, alteram os níveis dos vários elementos contidos nas diferentes classes de tamanho dos agregados $(\mathbf{5}, \mathbf{6})$.

(1) Trabalho apresentado ao IT Congresso Latino-Americano e $\mathbf{X}$ Congresso Brasileiro de Ciência do Solo, realizados em Piracicaba, em julho de 1965 . Recebido para publicação em 2 de marco de 1966. 
Tendo em vista estudar essas características das estruturas do latossolo roxo e do podzólico vermelho amarelo-orto, foram instalados ensaios em vasos com diferentes classes de tamanho de agregados dêsses solos, visando verificar as influências sôbre o desenvolvimento do milho, tomado como planta teste. $\mathrm{O} 3$ primeiros resultados dêsses ensaios são relatados neste trabalho.

\section{2 - MATERIAL E MÉTODOS}

Os agregados utilizados como substrato para o ensaio provieram de horizontes bem definidos dos seguintes solos:

- Latossolo roxo, sob floresta primária, da Estação Experimental de Ribeirão Prêto: horizonte superficial, $\mathrm{A}_{1}+\mathrm{A}_{3}$, de 0 a $26 \mathrm{~cm}$ de profundidade; horizonte profundo, $B_{21}$, de 26 a $50 \mathrm{~cm}$ de profundidade.

- Podzólico vermelho amarelo-orto, em pomar da Estação Experimental de Monte Alegre do Sul: horizonte superficial, $A_{1}+A_{2}$, de 0 a $25 \mathrm{~cm}$ de profundidade; horizonte profundo, $B_{21}$, de 25 a $60 \mathrm{~cm}$ de profundidade.

Foram colhidos, de cada horizonte, 250 a $300 \mathrm{~kg}$ de amostra, a fim de possibilitar a obtenção de uma quantidade suficiente de agregados de diversos tamanhos. As amostras, trazidas para o laboratório, foram sêcas ao ar e depois passadas nas peneiras de 7, 4,2 e $1 \mathrm{~mm}$ de abertura de malha, obtendo-se as classes de tamanho de agregados 7-4, 4-2, 2-1 e $<1 \mathrm{~mm}$.

O ensaio foi feito com duas repetições para cada tamanho de agregados, em vasos de $10 \mathrm{~cm}$ de diâmetro e $28 \mathrm{~cm}$ de altura, tendo sido plantada uma semente de milho em cada vaso.

As adições de água, a cada vaso, foram feitas da seguinte maneira: as primeiras regas, até o solo saturar-se de umidade, o que foi obtido com a adição de $160 \mathrm{~cm}^{3}$ de água. Posteriormente, e à razão de uma ou duas vêzes por semana, adicionaram-se $80 \mathrm{~cm}^{3}$ de água, a cada vaso, equivalentes a uma chuva de cêrca de $10 \mathrm{~mm}$. Em nenhum momento foram observados sinais de deficiência hídrica nas plantas.

O contrôle de crescimento foi feito através de medições de altura das plantas, a intervalos regulares, e da contagem do número de fôlhas. Esta última medida não apresentou variações dignas de nota, durante o transcorrer do ensaio, de modo que no quadro 1 só constam as referentes ao crescimento. As plantas foram retiradas dos vasos no $71 .^{\circ}$ dia, anotando-se o pêso da parte aérea. Fotografias do sistema radicular são apresentadas na figura 3 . 


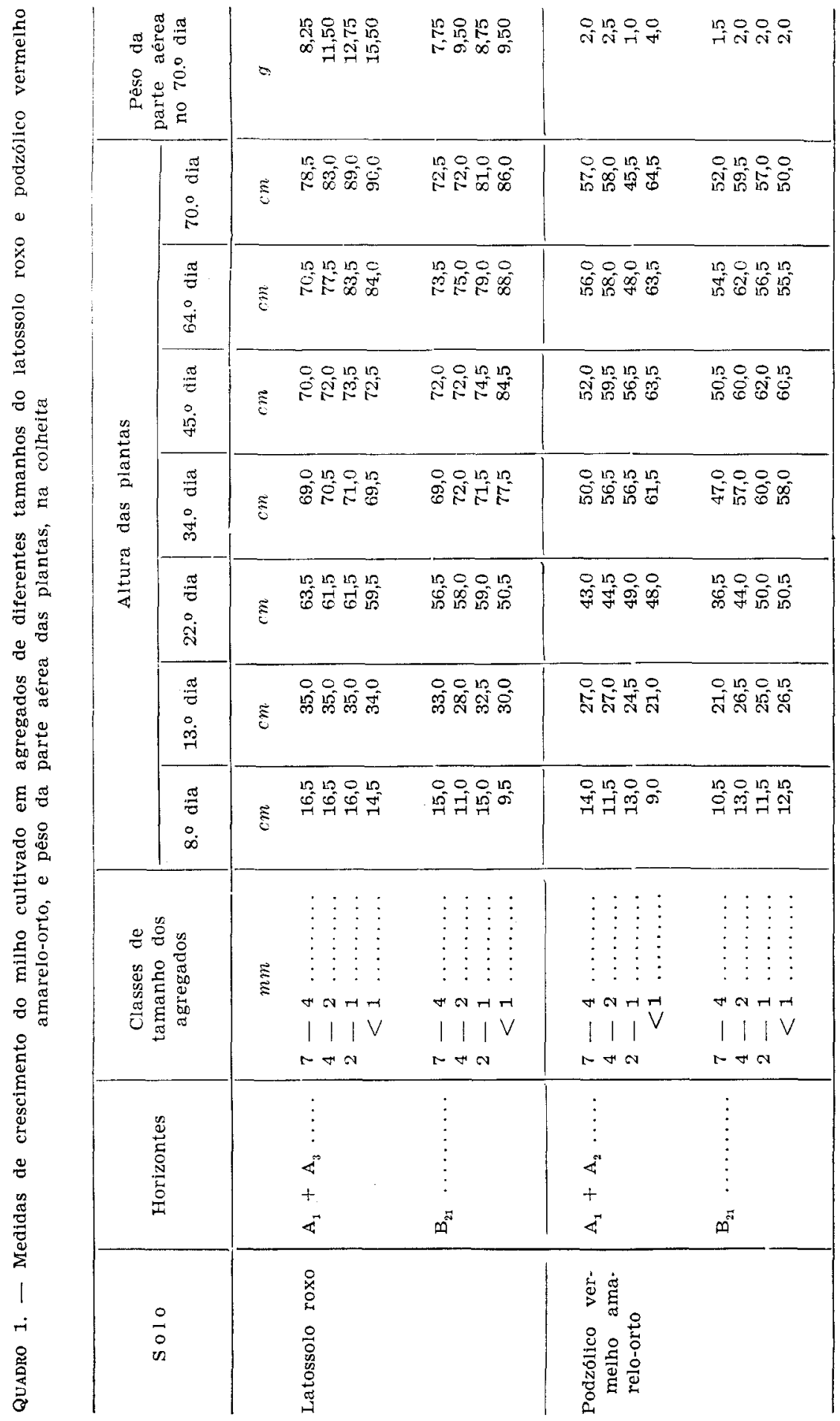




\section{3 - RESULTADOS E DISCUSSÃO}

As figuras 1 e 2 permitem visualizar a marcha do crescimento, cujos dados estão no quadro 1.

No latossolo roxo (quadro 1 e figura 1) o milho apresentou comportamento bastante semelhante nos dois horizontes estudados.

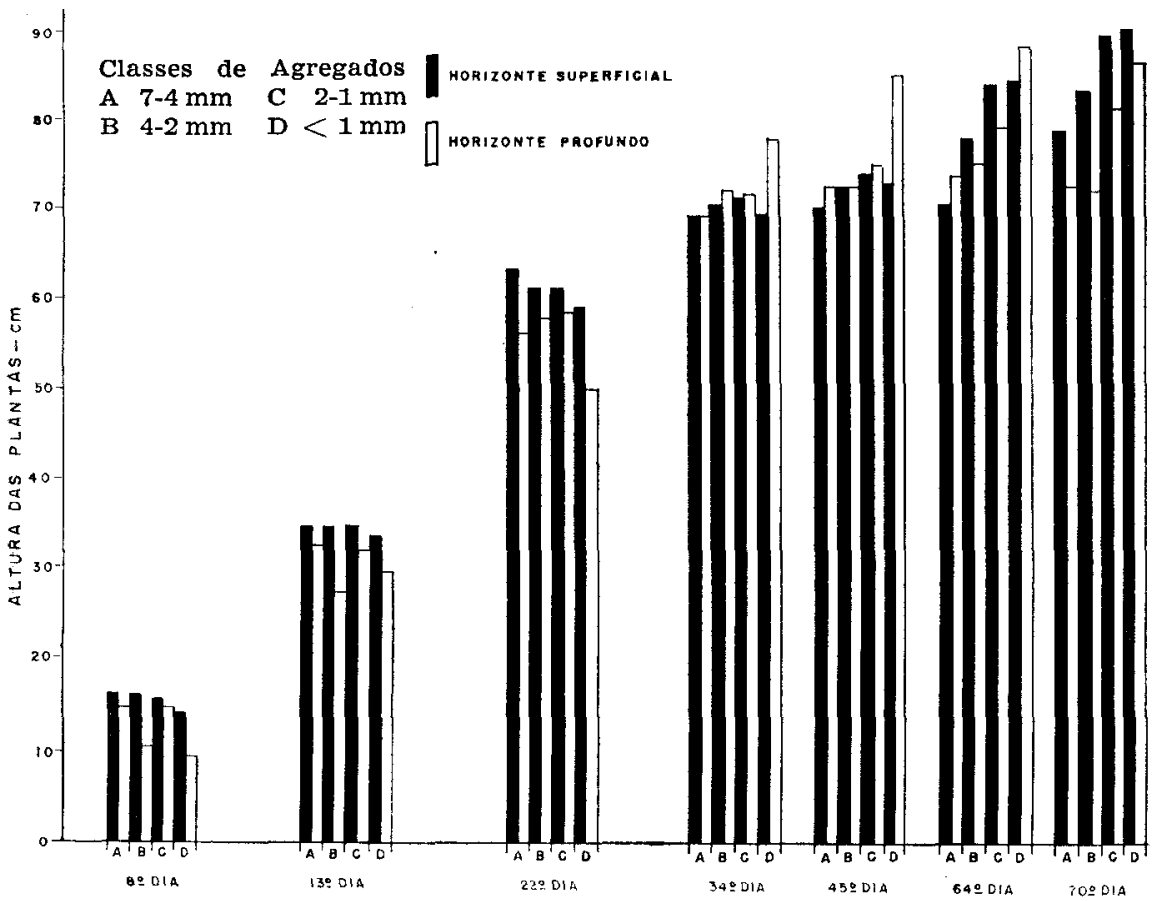

Figura 1. - Crescimento do milho cultivado em agregados de diferentes tamanhos do latossolo roxo.

Inicialmente, as plantas cultivadas em agregados maiores (7-4 e 4-2 $\mathrm{mm}$ ) apresentaram maior desenvolvimento do que nos agregados menores $(2-1 \mathrm{e}<1 \mathrm{~mm})$. Essa diferença foi bastante nítida no horizonte superficial até o $22 .^{\circ}$ dia, e no profundo, até o 13. dia; além disso, notou-se uma ligeira supremacia das plantas cultivadas no horizonte superficial.

No $34 .^{\circ}$ dia o maior crescimento foi observado nos agregados 2-1 $\mathrm{mm}$, seguido dos de 4-2 e $1 \mathrm{~mm}$, vindo por último 7-4 $\mathrm{mm}$. No horizonte profundo, essa tendência apareceu no $22 .^{\circ}$ dia, ao passo que no $34 .^{\circ}$ dia as plantas maiores foram observadas nos agregados menores. 
Do $45 .^{\circ}$ dia até o final do ensaio, as plantas cultivadas nos agregados menores que $1 \mathrm{~mm}$ apresentaram maior desenvolvimento, seguidas das dos agregados de 2-1, 4-2 e, finalmente, 7-4 mm. A partir do $64 .^{\circ}$ dia notou-se ligeira superioridade das plantas do horizonte superficial sôbre as do profundo.

O pêso da parte aérea, obtido no final do ensaio (quadro 1), confirma as medidas do crescimento. Sòmente as plantas do horizonte profundo, vasos $2-1 \mathrm{~mm}$, não confirmaram o maior crescimento da parte aérea.

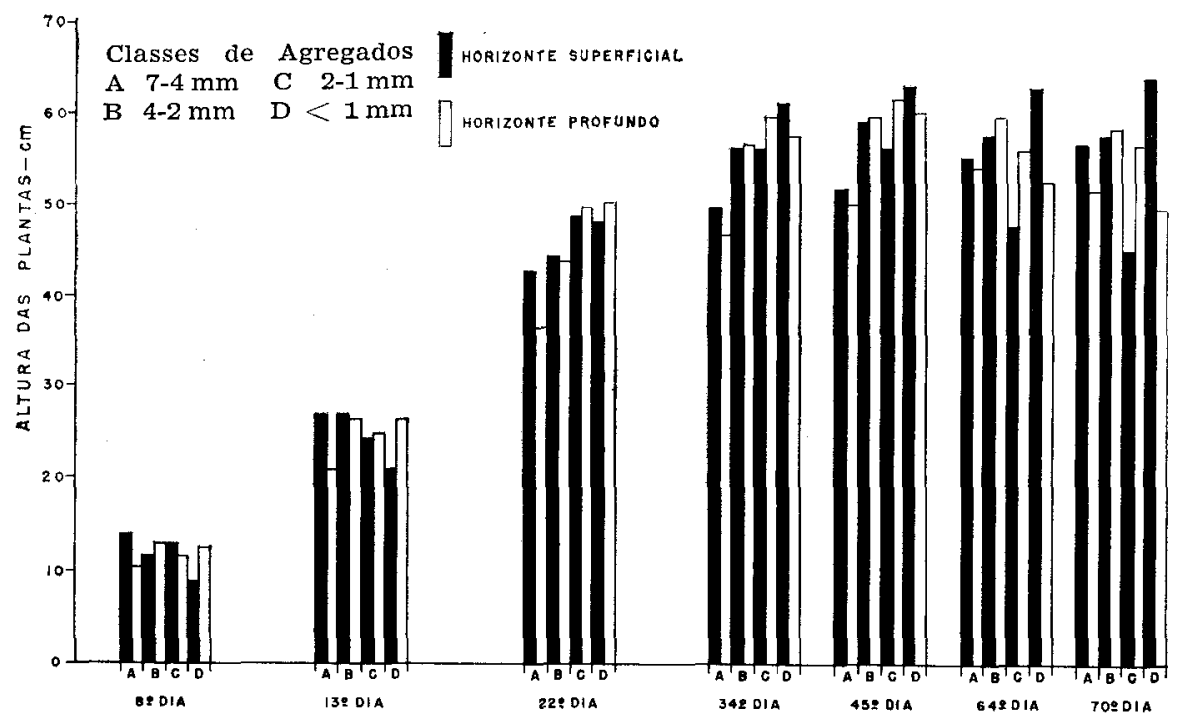

Figura 2. - Crescimento do milho em agregados de diferentes tamanhos do podzólico vermelho amarelo-orto.

As fotografias da figura 3 documentam um aspecto interessante do desenvolvimento do sistema radicular no latossolo roxo. Nas classes de agregados 7-4 e 4-2 mm, sobretudo na primeira, o sistema radicular, apesar de abundante, era constituído de raízes grossas e não muito fasciculadas, ao passo que nas classes menores que $2 \mathrm{~mm}$ o sistema radicular apresentou-se bem mais abundante do que nas anteriores, predominando ainda raízes finas e inteiramente fasciculadas. Êsses aspectos permitiram constatar que, no latossolo roxo, a área do sistema radicular foi bem maior nos agregados menores do que $2 \mathrm{~mm}$.

Estudos feitos anteriormente (5, 9) indicaram ocorrer uma variação dos níveis dos elementos nutrientes nos diversos tamanhos de agregados do latossolo roxo. 
Assim é que a classe $7-4 \mathrm{~mm}$ apresentava os teores mais altos, seguida de 4,2, < 1 e, finalmente, $2-1 \mathrm{~mm}$. Essa variação dos teores dos elementos nutrientes aparentemente não exerceu influência sôbre o desenvolvimento das plantas, pois as maiores, no final do ensaio, foram as obtidas nas duas classes menores que $2 \mathrm{~mm}$. Êsse fato leva a supor que a variação encontrada no desenvolvimento do milho seja devida às condições físicas do substrato dos vasos, confirmando o que o aspecto do sistema radicular deixa entrever. Assim, sob o ponto de vista fisiológico, as classes de agregados 2-1 e $1 \mathrm{~mm}$ seriam as mais adequadas para o desenvolvimento do milho, isto é, o latossolo roxo poderia sofrer pulverização sem que fôsse afetado o desenvolvimento das plantas. Isso explicaria, também, o fato registrado anteriormente (7), de que o cultivo do latossolo roxo provoca diminuição considerável no tamanho médio dos agregados, sem nenhuma influência sôbre a produção.

A figura 2 mostra o desenvolvimento do milho nos diferentes tamanhos de agregados do podzólico vermelho amarelo-orto. As mesmas observações feitas acima, a respeito do latossolo roxo, aplicam-se de forma geral. As diferenças iniciais entre agregados grosseiros e finos foram mais nítidas no horizonte superficial e mal definidas no profundo.

No horizonte superficial a inversão de crescimento foi observada a partir do $22 .^{\circ}$ dia, mais cedo, portanto, que no latossolo roxo. As plantas dos agregados mais finos $(1 \mathrm{~mm})$ passaram a apresentar maior desenvolvimento, e essa tendência acentuou-se até o final do ensaio. As plantas da classe de agregados 2-1 mm mostraram, a partir do $34 .^{\circ}$ dia de ensaio, tendência a diminuir de tamanho. No final do ensaio, verificou-se a razão: os dois vasos que continham êsses agregados apresentavam entupimento do sistema de drenagem, acumulando a água desde o primeiro dia e ocasionando o fenômeno registrado.

No horizonte profundo, as coisas se passaram de modo um pouco diferente. A partir do $45 .^{\circ}$ dia, as plantas dos agregados $2-1$ e $<1 \mathrm{~mm}$ começaram a apresentar nítida diminuição de tamanho, as de 4-2 mm conservaram o mesmo tamanho e as de 7-4 mm aumentaram um pouco. Porém, no final, tôdas as plantas, nas várias classes de tamanho de agregados, apresentavam diminuição de tamanho (comparar, por exemplo, as medidas dos $\operatorname{dias} 64 .^{\circ}$ e $700^{\circ}$ ).

As pesagens da parte aérea, no final do ensaio, confirmaram as medidas de crescimento. No horizonte superficial, as plantas de maior pêso corresponderam à classe de agregados $<1 \mathrm{~mm}$, podendo-se observar ainda o efeito depressivo do impedimento de drenagem nos vasos $2-1 \mathrm{~mm}$.

No horizonte profundo, a diminuição de tamanho das plantas dos agregados menores ficou registrada nos pesos iguais das classes de agregados 4-2, 2-1 e $<1 \mathrm{~mm}$. 
F. GROIMTIN \& 3OSE PEREIRA DE QUEIROZ NETO

Out., 1963 AGREGADOS E SISTEMA RADICULAR DO MILHO

259
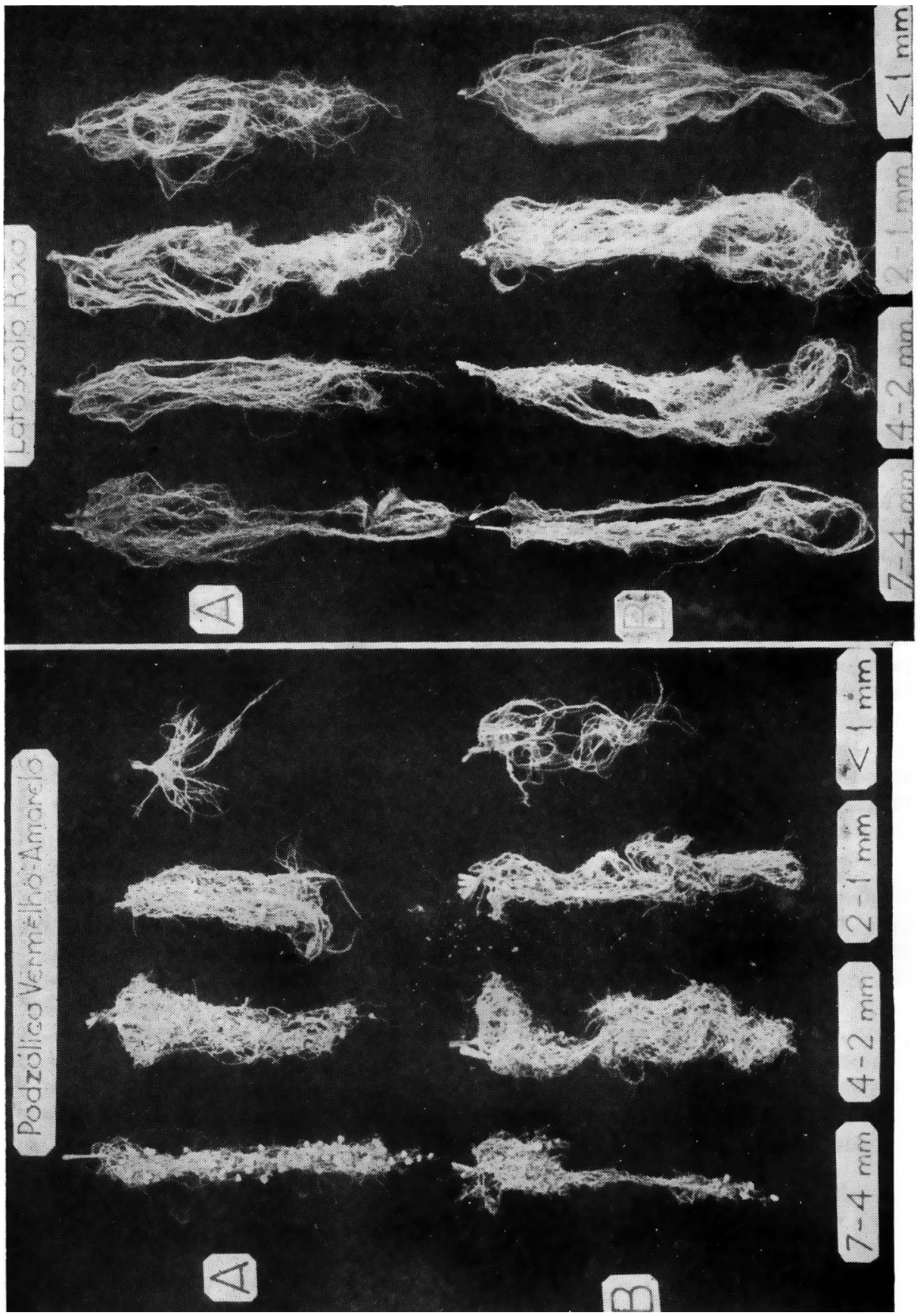
A fotografia do sistema radicular (figura 4) mostra certas particularidades do desenvolvimento da planta. $\mathrm{O}$ sistema radicular da classe $7-4 \mathrm{~mm}$, nos dois horizontes, foi abundante, mas constituído quase sòmente de raizes grossas. Nas classes 4-2 e 2-1 mm, o sistema radicular era exuberante e constituído de maior quantidade de raízes finas, sendo que êsse fato foi mais nítido na classe $4-2 \mathrm{~mm}$. Na classe de agregados $<1 \mathrm{~mm}$, o sistema radicular era raso e pequeno.

Certos aspectos apresentados pela parte aérea concordam com essas observações. A depressão no desenvolvimento, causada pelo impedimento de drenagem na classe $2-1 \mathrm{~mm}$ do horizonte superficial, foi atestada, de certa forma, por um desenvolvimento ligeiramente menor do sistema radicular. No entanto, não se explica a falta de desenvolvimento do sistema radicular das plantas, nos agregados menores que $1 \mathrm{~mm}$ do horizonte superficial, face ao maior desenvolvimento da parte aérea.

Da mesma forma que para o latossolo roxo, pode-se inferir que os principais causadores da variação do desenvolvimento das plantas de milho, no podzólico vermelho amarelo-orto, sejam de natureza física. Trabalhos anteriores indicaram que, nesse solo, a variação dos teores dos elementos nutrientes nas diferentes classes de tamanho de agregados era desprezível $(\mathbf{6}, \mathbf{9})$. Assim, pode-se admitir, sob o ponto de vista fisiológico, que as classes de tamanho de agregados do podzólico vermelho amarelo-orto mais adequadas para o desenvolvimento do milho sejam as de 4-2 e 2-1 $\mathrm{mm}$. Nas menores que $1 \mathrm{~mm}$, é possível que tenha ocorrido um impedimento físico, com um efeito semelhante à compactação, tornando o solo menos propício ao crescimento do sistema radicular.

Êsses resultados iniciais parecem também confirmar as observações de alguns autores (1), segundo os quais, para a germinação, o solo deveria conter 30 a $40 \%$ de agregados de diâmetro próximo ao da semente. O milho, de semente relativamente grande, apresentou maior crescimento inicial nas classes de agregados acima de $2 \mathrm{~mm}$. Por outro lado, o desenvolvimento posterior da planta far-se-ia de maneira mais rápida e com melhor aproveitamento das reservas de nutrientes do solo, se êste apresentasse condições que permitissem uma melhor disseminação e contato das raízes com a parte sólida (10), isto é, agregados menores que $2 \mathrm{~mm}$ ou, no máximo, menores que $4 \mathrm{~mm}$.

\section{4 - CONCLUSÕES}

Os ensaios de vasos, realizados com agregados de diferentes tamanhos do latossolo roxo e podzólico vermelho amarelo-orto, utilizando o milho como planta teste, permitem concluir: 
Os dois solos provocaram diferenças marcantes quanto ao comportamento da planta em função dos agregados estudados. Enquanto no latossolo roxo a classe de agregados $<1 \mathrm{~mm}$ favoreceu o crescimento da parte aérea e do sistema radicular do milho, no podzólico vermelho amarelo-orto essa vantagem foi observada nas classes de 4-2 e 2-1 mm.

Essa diferença fundamental entre as plantas cultivadas nos dois solos merece ser mais bem estudada. Parece que a causa da variação é de natureza física, e não de teores de nutrientes. Êsses estudos, além disso, podem oferecer subsídios para a compreensão da importância do preparo do solo para o cultivo.

As características do podzólico vermelho amarelo-orto, ao contrário do latossolo roxo, indicam que nos ensaios em vasos, e talvez no próprio campo, devem ser tomadas pręcauções contra a pulverização excessiva do solo, para evitar efeito de compactação, que dificulta o desenvolvimento do sistema radicular e o próprio desenvolvimento da parte aérea.

THE EFFECT OF AGGREGATE SIZE ON THE GROWING AND ON THE ROOT SYSTEM OF THE CORN PLANTS

\section{SUMMARY}

Dry aggregates were separated from the "latossolo roxo" and red-yellow podzolic-ortho soil to find out the effect of the size on the growing of aerial parts and on the development of the root system of the corn plant, grown in pots.

It was noted that the size of aggregates of the two soils presented great differences concerning the development of corn plants.

In the "latossolo roxo" the $<1.0 \mathrm{~mm}$ size class was the most appropriated for the plant growing and development of the root system. In the red-yellow podzolic-ortho soil, the best conditions for growing were presented by the size class 4.0 to 2.0 and 2.0 to $1.0 \mathrm{~mm}$ in diameter.

The variation for the growing of the aerial part and the root system might be attributed to the physical nature of the soil.

The intensive digging up of the red-yellow podzolic soil seems to have an unfavorable effect on the development of the root system of the corn plants.

\section{LITERATURA CITADA}

1. Demolon, A. Dynamique du sol. 5. ${ }^{\mathrm{a}}$ ed. Paris, Dunod, $1953.520 \mathrm{p}$.

2. GrohmanN, F. Análise de agregados de solos. Bragantia 19:[201]-213. 1960.

3. \& ARruda, H. V. Influência do preparo do solo sôbre a estrutura da terra-roxa-legitima. Bragantia 20:[1203]-1209. 1961. 
4. \& Conagin, A. Técnica para o estudo de estabilidade de agregados do solo. Bragantia 19:[329]-343. 1960.

5. Oliveira, J. B. \& QueIRoz, J. P. (neto). Influência da adubação nas características dos agregados do solo da série Chapadão (latossolo roxo). (No prelo)

6. - GrohmanN, F. \& Querroz, J. P. (neto). Caracteristicas dos agregados de um podzólico vermelho amarelo-orto da Estação Experimental de Monte Alegre do Sul. (No prelo)

7. QueIroz, J. P. (neto) \& GrommaNN, F. Estado de agregação da terraroxa (série Chapadão) num ensaio de adubação de milho. Bragantia $22:[635]-646.1963$.

8. - \& OliveirA, J. B. Características analíticas dos agregados dos solos latossolo roxo (série Chapadão) e podzólico vermelho amarelo-orto. (No prelo)

9. —_ Oliveira, J. B. \& GrohmanN, F. Características da estrutura de um podzólico vermelho amarelo-orto da Estação Experimental de-Monte Alegre do Sul. (No prelo)

10. Russell, J. Soil conditions and plant growth. $8^{\mathrm{a}}$ ed., revista por Russel, E. W. London, Longmans, Green \& Co., 1952.635 p. 